Agrotrópica 33(3): 197 - 204. 2021.

Centro de Pesquisas do Cacau, Ilhéus, Bahia, Brasil

\title{
DESEMPENHO DE NOVILHAS EM PASTAGENS FORMADAS PELOS CAPINS TIFTON 85, XARAÉS E MOMBAÇA, SOB LOTAÇÃO ROTATIVA
}

\author{
Cláudia de Paula Rezende ${ }^{1 *}$, José Marques Pereira ${ }^{1,2}$, Alberti Ferreira Magalhães ${ }^{1}$, Débora de \\ Carvalho Basto ${ }^{3}$, Bruno G.C. Homem ${ }^{4}$, Robert Michael Boddey ${ }^{4}$, Bruno José Rodrigues Alves ${ }^{4}$
}

${ }^{1}$ CEPLAC/CEPEC - km 22, Rod. Ilhéus/Itabuna, 45600-970, Ilhéus, Bahia, Brasil. claudia.rezende@agricultura.gov.br. josem.pereira@agricultura.gov.br. alberti.magalhaes@ agricultura.gov.br. ${ }^{2}$ Universidade Estadual de Santa Cruz - Campus Soane Nazaré de Andrade, Rodovia Ilhéus/Itabuna, km 16, Bairro Salobrinho, Ilhéus, Bahia, Brasil. ${ }^{3}$ Rua Doutor Portela,

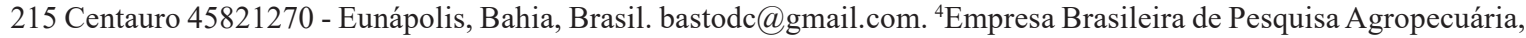
EMBRAPAAgrobiologia, Seropédica, RJ, Brasil. agrossizoo@hotmail.com. robert.boddey@embrapa.br, bruno.alves@embrapa.br.

* Autor para correspondência: claudiaprezende@hotmail.com

O experimento foi conduzido na Estação de Zootecnia do Extremo Sul (Essul), pertencente a Comissão Executiva do Plano da Lavoura Cacaueira (CEPLAC), localizada no município de Itabela - Bahia - Brasil. Com o objetivo de avaliar o ganho de peso individual e por unidade de área de novilhas girolandas manejadas sob lotação rotativa em três pastagens fertilizadas com nitrogênio e irrigadas. As pastagens foram de Tifton 85 , com 18 piquetes de $667 \mathrm{~m}^{2}$, Xaraés e Mombaça, ambos com 28 piquetes de $429 \mathrm{~m}^{2}$. O delineamento experimental foi em blocos casualizados com medidas repetidas no tempo ou por ciclo de pastejo. Com base em 224 dias de avaliações, não foram observadas diferenças significativas quanto ao ganho de peso por animal, por área e nem na lotação animal, ficando os ganhos por unidade de área entre 2,59 e 3,52 $\mathrm{kg} \mathrm{ha}^{-1}$ dia $^{-1}$ e a lotação entre 5,06 e 5,61 UA ha ${ }^{-1}$.

Palavras-chave: Dossel, ganho de peso, massa de forragem, oferta de forragem.

\footnotetext{
Heifers perfromance in pasture estabelished for the Tifton 85, Xaraes and Mombaça grass, under rotational stocking. The experiment was conducted at the Animal Husbandry Station of the Extreme South of Bahia (Essul), belonging to the Executive Committee of the Cocoa Plantation Plan (CEPLAC), located in the municipality of Itabela, Bahia. With the objective of evaluating the animal weight gain and per unit of area in Hostein-Gyr crossbred, managed under rotational stocking in three pastures fertilized with nitrogen and irrigated. The pastures were of Tifton 85, with 18 paddocks of $667 \mathrm{~m}^{2}$, Xaraes palissadegras and Mombasa guinea grass, both with 28 paddocks of $429 \mathrm{~m}^{2}$. The experimental design was in randomized blocks with repeated measurements over time or by grazing cycle. Based on 224 days of evaluations, there was no significant differences for weight gain per animal, by area or in animal stocking, with gains per unit of area between $2.59 \mathrm{~kg} \mathrm{ha}^{-1} \mathrm{day}^{-1}$ and $3.52 \mathrm{~kg} \mathrm{ha}^{-1} \mathrm{day}^{-1}$ and animal stocking between $5.06 \mathrm{AU}^{-1} \mathrm{ha}^{-1}$ and $5.61 \mathrm{AU} \mathrm{ha}^{-1}$.
}

Key words: Canopy, weight gain, forage mass, forage allowance. 


\section{Introdução}

O Brasil é o maior produtor e exportador de carne bovina do mundo, com um rebanho estimado em 218,2 milhões de cabeças, ocupando uma área de 165,2 milhões de hectares de pastagens, o que representa $20 \%$ do território nacional (IBGE, 2020; ABIEC, 2021). Cerca de $95 \%$ da carne bovina é produzida em regime de pastagens, graças ao baixo custo de produção em relação aos concentrados, constituindo-se a forma mais prática e econômica de alimentação de bovinos (Cunha et al., 2007). Segundo Barros et al. (2019), a disponibilidade de área, o baixo custo por quilograma de massa seca de forragem produzida, a diversidade de espécies forrageiras existentes e seu potencial de produção, tornam a produção de bovinos no Brasil, uma atividade mais atrativa, já que a base alimentar desses animais são as pastagens. Essa particularidade aumenta a competitividade do nosso produto no mercado internacional devido ao menor custo de produção, a não competitividade com a alimentação humana e ainda por conferir um diferencial qualitativo à carne brasileira, por esta não apresentar riscos associados ao uso de proteína animal na alimentação do rebanho (Embrapa, 2020). O processo de intensificação da produção de leite e de carne bovina, implica em uso de forrageiras com alta capacidade de produção de matéria seca, destacando-se as cultivares dos gêneros Pennisetum, Cynodon, Panicum e Brachiaria, em razão de seu elevado potencial produtivo e da sua qualidade (Alencar et al., 2009). Aliado a seleção de cultivares mais produtivas e de qualidade, estão também as práticas de fertilização, manejo do dossel e dos animais que utilizarão tais pastagens. De forma a atender os objetivos finais de qualquer atividade econômica, ou seja, a obtenção de produto em quantidade e qualidade a um menor custo, tanto financeiro e como ambiental.

$\mathrm{Na}$ atividade pecuária com frequência ocorre oscilações de ganho de peso animal em condições adversas do meio ambiente. Para reduzir esses problemas, estudos são realizados em busca de novas opções de espécies forrageiras com maior potencial de produção e menor sazonalidade na disponibilidade e qualidade da forragem, assim como adequação de manejo, que possam produzir maior impacto na produção animal.
A produção animal a pasto é resultado da eficiência dos processos de produção de forragem, consumo de forragem pelos animais e conversão da forragem em produto animal (desempenho animal), sendo a essência do manejo das pastagens atingir o balanço harmônico e eficiente desses três processos (Paulino et al., 2004). Quanto melhor a qualidade da forrageira, maiores ganhos serão obtidos por animal e menor será a oferta de forragem necessária, sendo fundamental a determinação da oferta de forragem que não limite o consumo pelo animal (Euclides, 2001).

Assim, esse trabalho foi proposto com o objetivo de avaliar o ganho de peso por unidade de área de novilhas manejadas sob lotação rotativa em pastagens formadas pelos capins Tifton, Xaraés e Mombaça.

\section{Material e Métodos}

O experimento foi conduzido na Estação de Zootecnia do Extremo Sul (Essul) da Comissão Executiva do Plano da Lavoura Cacaueira - CEPLAC, localizada em Itabela-Bahia (16 $39^{\circ}$ 'S e $\left.39^{\circ} 30^{\prime} \mathrm{O}\right)$. A área está sob o domínio do ecossistema de Mata Atlântica e o clima local é uma transição entre os tipos Af e Am, segundo a classificação de Köppen, com precipitação anual de $1311 \mathrm{~mm}$ e temperatura média de $25^{\circ} \mathrm{C}$, sem estação seca definida. Predominam os solos dos tipos Latossolo Amarelo Distrocoeso e Argissolo Amarelo Distrocoeso com textura arenosa na superfície e com o teor de argila aumentando ao longo do perfil, são ácidos e de baixa fertilidade natural, sendo o fósforo o elemento mais limitante, cujas características químicas médias na camada de $20 \mathrm{~cm}$ de profundidade apresentaram os seguintes valores: $\mathrm{pH} \mathrm{em} \mathrm{H}_{2} \mathrm{O}=5,9 ; \mathrm{Al}=0,0 \mathrm{cmol}_{\mathrm{c}} \mathrm{dm}^{-3} ; \mathrm{Ca}=1,9 \mathrm{cmol}_{\mathrm{c}}$ $\mathrm{dm}^{-3} ; \mathrm{Mg}=0,44 \mathrm{cmol}_{\mathrm{c}} \mathrm{dm}^{-3} ; \mathrm{K}=0,09 \mathrm{cmol}_{\mathrm{c}} \mathrm{dm}^{-3} ; \mathrm{P}$ disponível $=3 \mathrm{mg} \mathrm{dm}^{-3}$.

Os dados climáticos relativos ao período experimental foram obtidos na Estação Climatológica localizada na Estação Essul, pertencente ao Departamento da CEPLAC, e estão demonstrados na Figura 1.

A área experimental constou de 18 piquetes de $667 \mathrm{~m}^{2}$ de capim Tifton (Cynodon dactylon (L.) Pers cv. Tifton 85), 28 piquetes de $429 \mathrm{~m}^{2}$ de capim Xaraés (Uroclhoa brizantha (Hochst. Ex A. Rich.) Stapf. cv. Xaraés) e 28 piquetes de $429 \mathrm{~m}^{2}$ de capim Mombaça 
(Megathyrsus maximus cv. Mombaça), correspondendo a área de 1,2 ha para cada pastagem. Por ocasião do preparo do solo, foram utilizados $1200 \mathrm{~kg} /$ ha de calcário dolomítico e no plantio $80 \mathrm{~kg} \mathrm{ha}^{-1} \mathrm{de}_{2} \mathrm{O}_{5}$, realizadas em outubro e novembro de 2011 respectivamente. A correção da saturação de bases foi estimada para atingir $70 \%$ e a adubação fosfatada para atingir, ao longo de dois anos, $25 \mathrm{ppm}$ de $\mathrm{P}_{2} \mathrm{O}_{5}$. A correção do solo e a adubação fosfatada foram realizadas de uma única vez, enquanto que a fertilização nitrogenada e potássica foram parceladas e aplicadas a cada saída dos animais dos piquetes, de forma que ao final de cada de 12 meses, totalizasse $300 \mathrm{Kg} \mathrm{ha}^{-1}$ ano $^{-1}$ de nitrogênio e $240 \mathrm{~kg}$ de $\mathrm{K}_{2} \mathrm{O}$ ha $^{-1} \mathrm{ano}^{-1}$. Na correção na saturação de bases foi utilizado o calcário dolomítico e nas adubações de formação e manutenção utilizou-se o superfosfato simples, o cloreto de potássio e como fonte de nitrogênio a alternância de ureia e sulfato de amônio.

A irrigação da área experimental foi do tipo malha e ocorreu por meio de um sistema de aspersão com espaçamento de $15 \mathrm{~m}$ por $15 \mathrm{~m}$, com aspersores alternados. O manejo de irrigação foi realizado de forma suplementar, com turno de rega fixo de seis dias.
O experimento foi conduzido utilizando novilhas mestiças da raça girolando com aproximadamente 291 $\pm 55 \mathrm{~kg}$ de peso corporal, formando assim três lotes casualmente alocados em cada tratamento, segundo um delineamento em blocos casualizados com medidas repetidas no tempo, correspondendo aos ciclos de pastejo. Em função da oferta de forragem de $4 \%$ da massa verde, a cada ciclo de pastejo de 28 dias, foram feitos ajustes de lotação animal. As novilhas foram alocadas em dois grupos: testes e reguladoras. As quatro novilhas testes por pastagem, forneceram as informações de ganho de peso, e o somatório das novilhas testes e as reguladoras foram utilizadas no cálculo de lotação animal por unidade de área. Durante todo período de avaliação, a mistura mineral foi ofertada ad libitum a todos os animais.

A cada ciclo de pastejo foram avaliados a massa de forragem total, forragem verde (folhas + colmo), senescente, folhas verdes, colmo verdes, altura do dossel, e relação folha/colmo, tanto no pré como no pós-pastejo, além da oferta de forragem de massa verde e de folhas verdes, a taxa de lotação animal, e o ganho de peso por animal e por unidade de área.

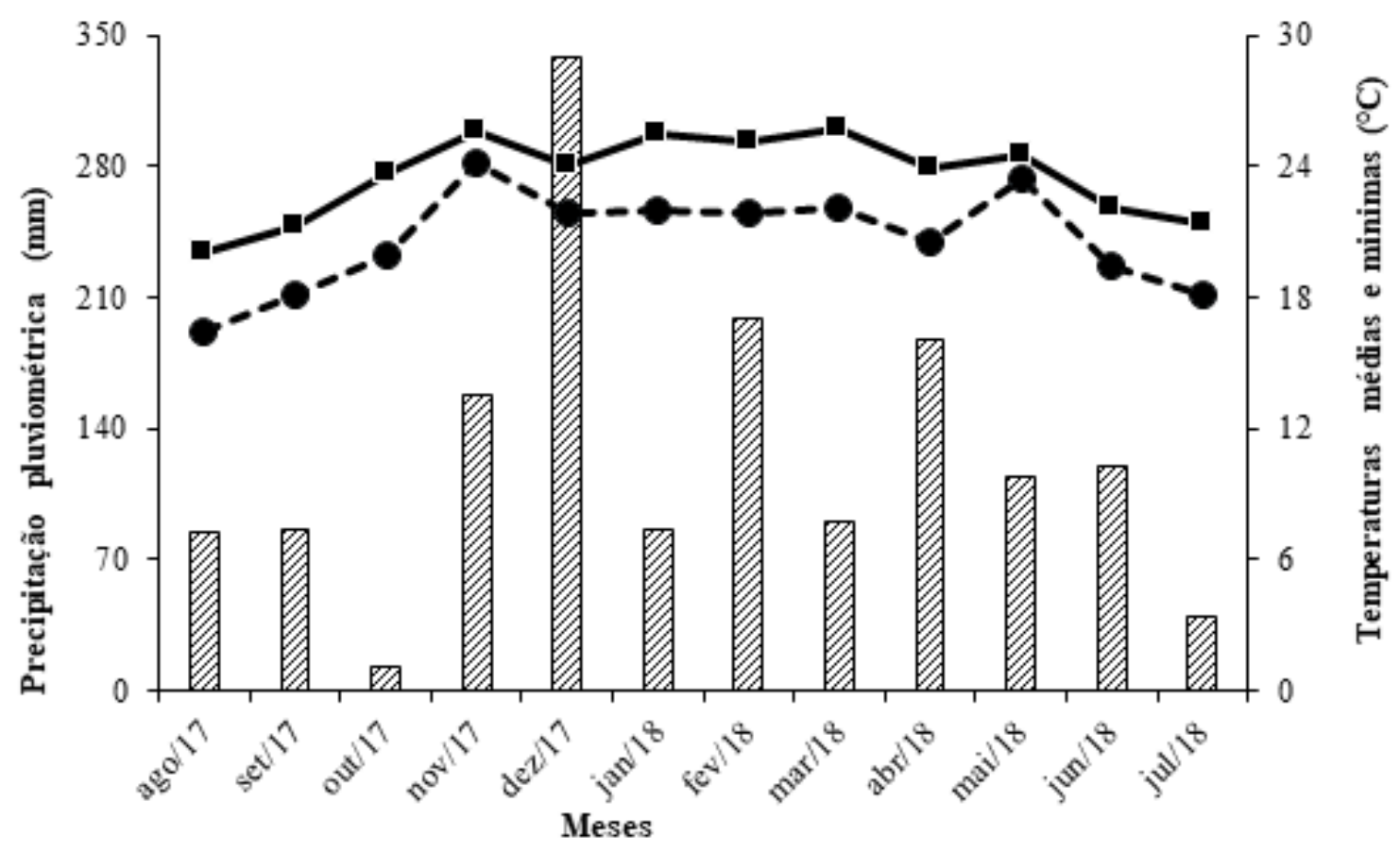

IIIIJ Precipitação $(\mathrm{mm})$ - - Temperatura minima $\left({ }^{\circ} \mathrm{C}\right)$ - - Temperatura m édia $\left({ }^{\circ} \mathrm{C}\right)$

Figura 1. Dados climatológicos do período de avaliação experimental. 
As avaliações ocorreram no intervalo de 02/08/2017 a 18/04/2018, ou seja, 08 ciclos de pastejo de 28 dias cada, não necessariamente consecutivos e assim distribuídos: $1^{\circ}\left(02 / 08 / 2017\right.$ a 30/08/2017), $2^{\circ}(31 / 08 /$ 2017 a $28 / 09 / 2017), 3^{\circ}(29 / 09 / 2017$ a $27 / 10 / 2017), 4^{\circ}$ $(28 / 10 / 2017$ a $25 / 11 / 2017), 5^{\circ}(05 / 10 / 2017$ a $02 / 01 /$ $2018), 6^{\mathrm{o}}(16 / 01 / 2018$ a $13 / 02 / 2018), 7^{\circ}(20 / 02 / 2018$ a $23 / 03 / 2018)$ e $8^{\circ}(21 / 03 / 2018$ a $18 / 04 / 2018)$.

Os dados foram submetidos à análise de variância e ao teste de homogeneidade de variância, sendo utilizado o procedimento ANOVA (para dados balanceados) dos recursos do software estatístico SAS (Statistical Analysis System, 2003). As comparações de médias foram efetuadas utilizando-se o teste de Tukey ao nível de 5\% de significância.

\section{Resultados e Discussão}

A massa de forragem verde (MV), de colmo (MC) e a altura do dossel (ALPR) no pré-pastejo e a massa de forragem verde (MVr), de colmo (MCr) e a altura do dossel (ALPO) no pós-pastejo diferiram entre as gramíneas $(\mathrm{P}<0,01)$, onde os maiores valores foram sempre observados para o capim Mombaça, seguido do Xaraés e por último o Tifton (Tabela 1 e 2). Enquanto no capim Xaraés e Mombaça, a massa de forragem total (MT), e de folhas verdes (MF) no prépastejo e as massas de forragem total (MTr), verde (MVr), senescente (MSr), de folhas (MFr) e de colmo $(\mathrm{MCr})$ no pós-pastejo, foram similares entre si e superiores ao capim Tifton $(\mathrm{P}<0,01)$ (Tabela 1 e 2$)$. A maior MV foi obtida no capim Mombaça, seguindo do capim Xaraés, e do capim Tifton, visto principalmente pelas distintas características morfogênicas e estruturais de cada espécie. Quanto à estrutura o capim Tifton é a forrageira que tem a maior contribuição de folhas na MV, seguido do capim Xaraés e por último o capim Mombaça, nas proporções aproximadas de 37\%, $31 \%$ e $25 \%$, respectivamente. Os conhecimentos dessas características, aliadas a quantidade e qualidade de forragem ofertada e consumida pelos animais, são indispensáveis para obter-se um manejo adequado de qualquer pastagem (Brâncio et al., 2003). E ainda, segundo Flores et al. (2008), numa mesma espécie forrageira as características estruturais do dossel, o consumo de forragem e a produtividade, a exemplo nos capins Marandu e Xaraés, requerem práticas de manejo diferenciadas, tais como as alturas de pastejo.

Com o pastejo ocorreu uma redução na MV na ordem de $35,4 \%, 41,7 \%$ e $41,1 \%$, nos capins Tifton, Xaraés e Mombaça respectivamente. Já na MF essa redução foi de $58,9 \%, 34,1 \%$ e $35,3 \%$ na mesma sequência de citação das forrageiras. Indicando que no capim Tifton na redução de MV $(35,4 \%)$, estão incluídos também os colmos, pois por serem mais finos e tenros, foram consumidos pelos animais (Tabelas 1 e 2).

As alturas dos dosséis no pré e pós-pastejo diferiram entre as forrageiras. No Mombaça foi maior, seguido do Xaraés e Tifton (Tabelas 1 e 2). As alturas póspastejo foram $78,1 \%, 72,3 \%$ e $66,6 \%$ da altura do prépastejo, com redução da altura do pré-pastejo ou eficiência de pastejo de 21,9\%. 27,7\% e 34,4\%, respectivamente para os capins Tifton, Xaraés e Mombaça, mostrando que a altura do resíduo póspastejo ficou acima da altura em geral preconizado, que é da ordem de $50 \%$ da altura pré-pastejo.

Tabela 1. Média de massa de forragem total (MT), verde (MV), senescente (MS), folhas verdes (MF), colmo (MC), altura de plantas no pré-pastejo (ALPR), relação folha/colmo e percentagem de oferta de massa verde (OFMV) e de folhas verdes (OFMFV), em pastagens de Tifton, Xaraés e Mombaça

\begin{tabular}{|c|c|c|c|c|c|c|c|c|c|}
\hline \multirow{3}{*}{ Pastagem } & \multicolumn{9}{|c|}{ Pré-pastejo } \\
\hline & \multicolumn{5}{|c|}{ Massa de Forragem $\left(\mathrm{kg} \mathrm{ha}^{-1}\right)$} & \multirow{2}{*}{$\begin{array}{c}\text { Altura (cm) } \\
\text { ALPR }\end{array}$} & \multirow{2}{*}{$\begin{array}{c}\text { Relação } \\
\text { Folha/colmo }\end{array}$} & \multicolumn{2}{|c|}{ Of. de forragem $(\%)$} \\
\hline & MT & MV & MS & MF & MC & & & OFMV & OFMFV \\
\hline Tifton & $2.803,7 \mathrm{~b}$ & $1.995,3 \mathrm{c}$ & $808,4 \mathrm{a}$ & $737,4 \mathrm{~b}$ & $1.257,9 \mathrm{c}$ & $34,7 \mathrm{c}$ & $0,70 \mathrm{a}$ & $4,8 \mathrm{~b}$ & $1,9 \mathrm{~b}$ \\
\hline Xaraés & $5.723,6 \mathrm{a}$ & $4.358,9 \mathrm{~b}$ & $1.354,7 \mathrm{a}$ & $1.342,3 \mathrm{a}$ & $3.026,7 \mathrm{~b}$ & $51,28 \mathrm{~b}$ & $0,86 \mathrm{a}$ & $6,5 \mathrm{~b}$ & $2,2 \mathrm{~b}$ \\
\hline Mombaça & $7.238,3 \mathrm{a}$ & $5.876,9 \mathrm{a}$ & $1.361,4 \mathrm{a}$ & $1.456,8 \mathrm{a}$ & $4.420,2 \mathrm{a}$ & $76,9 \mathrm{a}$ & $0,47 \mathrm{a}$ & $9.8 \mathrm{a}$ & $2,8 \mathrm{a}$ \\
\hline Dms & 1523,3 & 1284,2 & 652,6 & 206,6 & 1189,7 & 16,2 & 0,51 & 2,05 & 0,7 \\
\hline
\end{tabular}

As médias seguidas de mesma letra não diferem estatisticamente entre si, pelo Teste de Tukey a $5 \%$. 
Tabela 2. Média de massa de forragem total (MTr), verde (MVr), senescente (MSr), folhas verdes (MFr), colmo (MCr), altura de plantas no pós-pastejo (ALPO), e relação folha/colmo, em pastagens de Tifton, Xaraés e Mombaça

\begin{tabular}{|c|c|c|c|c|c|c|c|}
\hline \multirow{3}{*}{ Pastagem } & \multicolumn{7}{|c|}{ Pós-pastejo } \\
\hline & \multicolumn{5}{|c|}{ Massa de Forragem $\left(\mathrm{kg} \mathrm{ha}^{-1}\right)$} & \multirow{2}{*}{$\begin{array}{c}\text { Altura (cm) } \\
\text { ALPO }\end{array}$} & \multirow{2}{*}{$\begin{array}{c}\text { Relação } \\
\text { Folha/colmo }\end{array}$} \\
\hline & MTr & MVr & MSr & MFr & $\mathrm{MCr}$ & & \\
\hline Tifton & $1.957,3 \mathrm{~b}$ & $1.289,9 \mathrm{~b}$ & $417,6 \mathrm{~b}$ & $302,9 \mathrm{~b}$ & $987,0 \mathrm{~b}$ & $27,1 \mathrm{c}$ & $0,32 \mathrm{a}$ \\
\hline Xaraés & $4.245,8 \mathrm{a}$ & $2.539,7 \mathrm{a}$ & $1.055,8 \mathrm{a}$ & 885,3 a & $1.654,4 \mathrm{a}$ & $37,1 b$ & $0,88 \mathrm{a}$ \\
\hline Mombaça & $4.627,4 \mathrm{a}$ & $3.165,6 \mathrm{a}$ & $942,4 \mathrm{a}$ & $942,4 \mathrm{a}$ & $2.223,2 \mathrm{a}$ & $51,2 \mathrm{a}$ & $0,70 \mathrm{a}$ \\
\hline Dms & 921,8 & 758,8 & 386,3 & 241,5 & 841,2 & 7,4 & 0,64 \\
\hline
\end{tabular}

As médias seguidas de mesma letra não diferem estatisticamente entre si, pelo Teste de Tukey a $5 \%$.

Segundo Euclides et al. (2014) o melhor momento para interromper o processo de crescimento do capim Mombaça, através do pastejo, é quando o dossel apresenta $95 \%$ de interceptação de luz, com a altura aproximada de $90 \mathrm{~cm}$, garantindo a oferta de uma forragem de qualidade. Esses estudos mostram alta correlação entre a altura do dossel e interceptação luminosa, indicando que a altura do dossel poderia ser usada como alvo de manejo confiável para monitoramento da frequência de pastejo. No entanto, Ribeiro et al. (2009) manejando a mesma forrageira a uma altura no pré-pastejo de $130 \mathrm{~cm}$ e uma densidade volumétrica de $0,69 \mathrm{~kg} \mathrm{~m}^{-3}$, consideraram essa altura a mais propicia à apreensão pelos animais e com maior proporção de folhas. No que tange à altura pós-pastejo, não havendo restrição de pastejo, Garcia et al. (2011) observaram que alturas no póspastejo do capim Mombaça entre 30 e $50 \mathrm{~cm}$, garantiram ganhos de $850 \pm 240 \mathrm{~g} \mathrm{dia}^{-1}$. Resultados similares foram obtidos por Euclides et al. (2014), confirmando que, sob pastejo rotativo deve-se manter uma altura de $50 \mathrm{~cm}$ no pós-pastejo, garantindo uma eficiência média de pastejo de $62 \%$. Assim, sendo mantida a eficiência de pastejo na faixa de 50 a $60 \%$, haverá uma otimização dos ganhos de peso por animal e por área (Carvalho, Canto e Moraes, 2004). No presente estudo as alturas do capim Mombaça no pré-pastejo foram inferiores ao obtidos na literatura consultada, mas as obtidas no pós-pastejo estão de acordo com os manejos de Garcia et al. (2011) e Euclides et al. (2014), levando a deduzir que a eficiência do pastejo nessa forrageira ficou dentro da faixa de $60 \%$.
Para o capim Xaraés, as alturas no pré e pós-pastejo foram acima das observadas na literatura consultada. Por exemplo, Carloto et al. (2011) ao avaliarem o desempenho animal e as características do dossel, observaram que alturas de pastejo a $15 \mathrm{~cm}$ promoveram maior percentagem de folhas e menor de colmos, quando comparadas as alturas de pastejo 30 e $45 \mathrm{~cm}$, visto que ocorreu um maior controle de alongamento de colmo. Para esses autores as alturas do capim Xaraés devem ficar entre 15 e $30 \mathrm{~cm}$ sob lotação contínua, pois combinam a maior percentagem de folhas, com um maior valor nutritivo da forragem consumida e consequentemente maior ganho de peso animal.

É importante ressaltar que geralmente, o aumento da intensidade de pastejo resulta em melhoria da eficiência de pastejo. Entretanto, a produção por animal é reduzida. Reforçando a importância de se avaliar a resposta do animal para se definir o resíduo pós- pastejo adequado para otimizar as produções por animal e por área (Euclides et al., 2014). Sendo muito importante utilizar um manejo que promova a sustentabilidade da pastagem.

As ofertas de forragem foram também distintas, variando de $9,8 \%$ a $4,8 \%$ na $\mathrm{MV}$ e $2,8 \%$ a $1,9 \%$ na MF $(\mathrm{P}<0,01)$. A maior oferta de forragem calculada para MV e MF, ocorreu no capim Mombaça, não diferindo para os demais capins (Tabela 1). Como são forrageiras de hábito de crescimento diferentes, há também diferenças na contribuição de cada uma das frações da planta no dossel. No capim Mombaça a contribuição dos colmos é elevada, indicado pela baixa relação folha/colmo de 0,47 , mesmo com o ajuste de 
pastejo, o que diretamente influencia na qualidade da MV ofertada aos animais. O dossel mantido mais alto com uma maior biomassa de forragem verde, porém com proporção crescente de colmos, acarreta acentuado comprometimento da relação folha/colmo (Cândido et al., 2005). Essa afirmativa é também válida para o capim Xaraés, que tem entre as forrageiras estudadas maior similaridade com a estrutura de dossel do Mombaça. Já no capim Tifton as folhas e os colmos são bem afilados e como já mencionado, com o pastejo os colmos são tão bem consumidos como as folhas.

As ofertas de massa de forragem verde para os capins Tifton e Xaraés foram similares com valor médio de 5,7 \%. Enquanto a oferta de massa de forragem de folhas verdes, foi maior para o Mombaça e menor para o capim Tifton. Muito embora o Mombaça tenha tido maior oferta de massa de forragem tanto verde, quanto de lâminas verdes, isso não refletiu em maior rendimento animal por unidade de área. Os ganhos de peso e lotação animal, não diferiram entre as pastagens, no entanto, em valores absolutos o capim Tifton foi o que teve maior ganho de peso animal por unidade de área, com ganhos 2,1\% e 26,4\% superiores ao capim Xaraés e Mombaça, respectivamente (Tabela 3), corroborando com os resultados obtidos por Maixner et al. (2009), que demonstraram que em uma oferta de lâminas foliares de $4 \%$, o capim Tifton foi capaz de manter sua capacidade produtiva e capacidade suporte por dois anos consecutivos, não ocorrendo o mesmo com o capim Elefante Anão .

Garcia et al. (2011), com estudo em capim Mombaça e capim Napier, observaram que a superioridade do capim Napier foi amenizada e mesmo

Tabela 3. Média de ganho de peso por animal e por unidade de área, taxa de lotação e rendimento animal, em pastagens de Tifton, Xaraés e Mombaça

\begin{tabular}{|c|c|c|c|c|}
\hline \multirow{2}{*}{ Pastagem } & \multicolumn{2}{|c|}{ Ganho de Peso } & \multirow{2}{*}{$\begin{array}{l}\text { Taxa de } \\
\text { lotação } \\
\text { UA. ha-1 }\end{array}$} & \multirow{2}{*}{$\begin{array}{c}\text { Rendimento } \\
\text { Arrobas ha } \\
\text { ano }^{-1}\end{array}$} \\
\hline & Kg animal ${ }^{1}$ dia $^{-1}$ & $\mathrm{Kg} \mathrm{ha}^{-1} \mathrm{dia}^{-1}$ & & \\
\hline Tifton & $0,451 \mathrm{a}$ & $3,5 \mathrm{a}$ & $5,6 \mathrm{a}$ & $42,8 \mathrm{a}$ \\
\hline Xaraés & $0,448 \mathrm{a}$ & $3,4 \mathrm{a}$ & $5,4 \mathrm{a}$ & $41,9 \mathrm{a}$ \\
\hline Mombaça & $0,441 \mathrm{a}$ & $2,6 \mathrm{a}$ & $5,1 \mathrm{a}$ & $31,5 \mathrm{a}$ \\
\hline $\mathrm{dms}$ & 0,2 & 1,4 & 0,8 & 16,9 \\
\hline
\end{tabular}

As médias seguidas de mesma letra não diferem estatisticamente entre si, pelo Teste de Tukey a $5 \%$. anulada, quando se tratava da produção de biomassa de folhas verdes, uma vez que o capim Mombaça apresentava maior proporção de folhas. De acordo com Carloto et al. (2011), além da altura, a oferta de forragem pode limitar o consumo pelos animais. Esses autores obtiveram correlação positiva entre o consumo de matéria seca de forragem e a oferta de matéria seca e de lâminas foliares. Para Fernandes et al. (2015) a maior oferta pode influenciar positivamente na seletividade e consumo de forragem, possibilitando em capim Marandu maior aporte de nutrientes e ganho de peso. Entretanto em capim Mombaça, Alexandrino et al. (2005) observaram que numa oferta de forragem de $10 \%$, ao final do período de pastejo, os animais demonstraram aparente desinteresse em continuar a apreensão de folhas residuais, em função do difícil acesso, apesar da relação folha/colmo ser relativamente alta. Nesse contexto, Carvalho et al. (2001) alegaram que o consumo máximo de massa de forragem é obtido quando a oferta é de pelo menos três vezes o potencial de ingestão do animal.

Não foram observadas diferenças significativas $(\mathrm{P}>0,05)$ quanto ao ganho de peso por animal, por área e por lotação animal, ou na estimativa de produção de carne anual, obtendo-se médias de respectivamente, 0,447 $\mathrm{kg}$ animal $^{-1} \mathrm{dia}^{-1}, 3,2 \mathrm{~kg} \mathrm{ha}^{-1} \mathrm{dia}^{-1}, 5,4 \mathrm{UA} \mathrm{ha}^{-1} \mathrm{e}$ 38,7@ ha ${ }^{-1}$ ano $^{-1}$. Embora não tenha havido diferença estatística as médias sugerem que os capins Tifton e Xaraés podem ser superiores ao capim Mombaça, especialmente no ganho de peso diário por ha e projeção de produção anual por ha, dependendo do tipo de manejo utilizado (Tabela 3).

A produção animal, medida através do ganho de peso, é um reflexo da disponibilidade de forragem; da forma como ela se apresenta ao longo do perfil do pasto; da habilidade dos animais em apreender a forragem, resultando em maiores ou menores consumos e, finalmente do valor nutritivo da forragem consumida (Brâncio et al., 2003). Segundo esses autores, a participação de folhas, o teor de proteína da dieta selecionada e o tamanho do bocado foram os que mais influenciaram positivamente o ganho de peso animal.

Os resultados aqui obtidos para ganho de peso por animal foram em geral inferiores e as taxas de lotação superiores aos dados correntes na 
literatura. Para o capim Tifton, Scaglia \& Boland (2014) obtiveram ganhos de $0,55 \mathrm{~kg}$ novilhos ha-1, com taxa de lotação de 2,3 novilhos ha-1. Em outro trabalho foi observado que o capim Xaraés em lotação contínua e alturas do pasto programadas para $15 ; 30$ e $45 \mathrm{~cm}$, os ganhos de peso diários animal ${ }^{-1}$ foram de $0,81,0,76$ e $0,61 \mathrm{~kg}$ correspondentes às lotações de 3,$5 ; 2,5$ e 2,0 $\mathrm{UA} \mathrm{ha}^{-1}$, respectivamente (Carloto et al., 2011). Já em capim Mombaça, Garcia et al. (2011) obtiveram ganhos médios de $0,85 \mathrm{~kg} \mathrm{dia}^{-1}$, num sistema de pastejo não restritivo e quando houve restrição de forragem esses ganhos caíram para $0,14 \mathrm{~kg} \mathrm{dia}^{-1}$. Ainda em capim Mombaça, Alexandrino et al. (2005), obtiveram ganhos de 0,824 e $0,760 \mathrm{~kg}$ novilho $\mathrm{ha}^{-1}$, com respectivas lotações de 3,65 e 3,39 novilhos ha ${ }^{-1}$, ao longo de um período experimental de 144 dias.

No contexto dos resultados obtidos nesse trabalho, onde os ajustes da taxa de lotação foram estabelecidos em função da forragem verde oferecida, onde a proporção de folhas era baixa e as ofertas de forragens obtidas a exceção do capim Mombaça, foram relativamente baixas, podem explicar os baixos ganhos de peso por animal obtidos. E em última instância, são consequência da baixa qualidade estrutural das pastagens e da baixa seletividade possibilitada aos animais. Com os ganhos de peso por animal baixos as produções por hectare, dependeram basicamente das taxas de lotação que foram consideravelmente elevadas, principalmente nos capins Tifton e Xaraés.

Os dados obtidos também sugerem que os ajustes de taxa de lotação, considerando as diferenças morfológicas e estruturais forrageiras, estolonífera, semi-decumbente e cespitosa, e diferentes relações folha/colmo, devem levar em consideração diferentes níveis de oferta de forragem.

\section{Conclusões}

- Os capins Tifton, Xaraés e Mombaça promoveram ganho de peso por animal, por hectare e taxa de lotação similares;

- A altura do dossel no pré-pastejo e a baixa oferta de folhas verdes, limitaram o consumo e prejudicado os ganhos por animal;

- A maior relação folha/colmo foi obtida no capim Xaraés, mesmo com alturas de pré e pós-pastejo relativamente altas.

\section{Literatura Citada}

ASSOCIAÇÃO BRASILEIRA DAS INDÚSTRIAS EXPORTADORAS DE CARNES - ABIEC. 2021. Beef Report - Perfil da Pecuária no Brasil. Disponível em: $<$ http://abiec.com.br/publicações/ beef-report-2021/> Acesso em: 30 set. 2021.

ALENCAR, C. A. de. et al. 2009. Produção de capins cultivados sob pastejo em diferentes lâminas de irrigação e estações anuais. Revista Brasileira de Engenharia Agrícola e Ambiental 13(6):680-686.

ALEXANDRINO, E. et al. 2005. Características morfogênicas e estruturais da Brachiaria brizantha cv. Marandu submetida a diferentes doses de nitrogênio e frequências de cortes. Acta Scientiarum Agronomy 27(1):17-24.

BARROS, J. S. et al. 2019. Valor nutritivo do capimXaraés em três intensidades luminosas. Arquivo Brasileiro de Medicina Veterinária e Zootecnia 71(5):1703-1711.

BRÂNCIO, P. A. et al. 2003. Avaliação de três cultivares de Panicum maximum Jacq. sob pastejo: comportamento ingestivo de bovinos. Revista Brasileira de Zootecnia 32:1045-1053.

CÂNDIDO, M. J. D. et al. 2005. Morfofisiologia do dossel de Panicum maximum cv. Mombaça sob lotação intermitente com três períodos de descanso. Revista Brasileira de Zootecnia, 34(2):406-415.

CARLOTO, M. N. et al. 2011. Desempenho animal e características de pasto de capim-Xaraés sob diferentes intensidades de pastejo, durante o período das águas. Pesquisa Agropecuária Brasileira 46(1):1-8.

CARVAlHO, P. C. F.; CANTO, M. W.; MORAES, A. 2004. Fontes de perdas de forragem sob pastejo: forragem se perde? In: Pereira, O. G.; Obeid, J.A; Fonseca, A.D. et al (eds). II Simpósio sobre manejo estratégico da pastagem, 2004, Viçosa, MG. Anais... Viçosa, MG: Universidade Federal de Viçosa. pp.387-418.

CARVALHO, P. C. F. et al. 2001. Importância da estrutura da pastagem na ingestão e seleção de dietas pelo animal em pastejo. In: Mattos, W. R. 
S. (Org.). A produção animal na visão dos brasileiros. 1 ed. Piracicaba, SP, FEALQ. pp.853-871.

CUNHA, F. F. et al. 2007. Características morfogênicas e perfilhamento do Panicum maxium Jacq. cv. Tanzânia irrigado. Ciência e Agrotecnologia 31(3):628-635.

EMBRAPA. 2020. Qualidade da carne, do campo a mesa/carne bovina/ Pastagem. Disponível em: $<$ https://www.embrapa.br/qualidade-dacarne> Acesso em: 21 dez. 2020.

EUCLIDES, V. P. B. 2001. Produção intensiva de carne bovina a pasto. In: Simpósio de Produção de Gado de Corte, 2., 2001, Viçosa, MG. Anais... Viçosa, MG: Universidade Federal de Viçosa. pp.55-82.

EUCLIDES, V. P. B.; MONTAGNER, D. B.; BARBOSA, R. A.; NANTES, N. N. 2014. Manejo do pastejo de cultivares de Brachiaria brizantha (Hoschst) stapf e de Panicum maximum Jacq. Revista Ceres (Brasil) 61 (Suplemento):808-818.

FERNANDES, L. de O. et al. 2015. Desempenho de bovinos da raça Gir em pastagem de Brachiaria brizantha submetidos a diferentes manejos. Revista Brasileira de Saúde e Produção Animal 16(1):36-46.

FLORES, R. S. et al. 2008. Desempenho animal, produção de forragem e características estruturais dos capins Marandu e Xaraés submetidos a intensidades de pastejo. Revista Brasileira de Zootecnia 37(8):1355-1365.

GARCIA, C. de S. et al. 2011. Desempenho de novilhos mantidos em pastagens de capim-elefante e capim-Mombaça. Revista Brasileira de Zootecnia 40(2):403-410.

IBGE - Instituto Brasileiro de Geografia e Estatística, Censo Agropecuário. (2020). Disponível em: < https://censos.ibge.gov.br > Acesso em 30 set. 2021.

MAIXNER, A. R. et al. 2009. Desempenho animal e produtividade de pastagens tropicais no noroeste do Rio Grande do Sul. Arquivo Brasileiro de Medicina Veterinária e Zootecnia 61(4):927-934.

PAULINO, M. F. et al. 2004. Suplementação de bovinos em pastagens: uma visão sistêmica. In: Simpósio de Produção de Gado de Corte, 4., 2004. Viçosa. Anais... Viçosa: UFV, 2004. pp. 93-144.

RIBEIRO, E. F. et al. 2009. Influência da irrigação, nas épocas seca e chuvosa, na produção e composição química dos capins Napier e Mombaça em sistema de lotação intermitente. Revista Brasileira de Zootecnia 38(8):1432-1442.

STATISTIC ANALYSIS SYSTEM - SAS. 2003. SAS/ STAT $^{\circledR}$ 14.1 User's Guide 9. SAS Institute Inc. Cary, NC, USA.

SCAGLIA, G.; BOLAND, H. T. 2014. The effect of bermudagrass hybrid on forage characteristics, animal performance, and grazing behavior of beef steers. Journal of Animal Science 92(3):1228-1238. 